\title{
Penerapan Fire Safety Management pada Bangunan Gedung Grand Slipi Tower Dikaitkan dengan Pemenuhan Peraturan dan Standar Teknis Proteksi Kebakaran
}

\author{
Moch. Ichwan Nur Effendie ${ }^{1}$, \\ Teknik Sipil Universitas Suryakancana \\ Jl Pasir Gede Raya, Cianjur \\ ${ }^{1}$ ichwan.one@gmail.com
}

Dikirimkan: 11, 2017. Diterima: 12, 2017. Dipublikasikan: 12,2017.

\begin{abstract}
Fire protection systems are basically consist of active fire protections which need energy (energized system), passive fire protection named as Built-in system, and Fire Safety Management (FSM), which is known as Human system. This thesis investigated the FSM aspect, since from many fire incidences, the main problems are often caused by less attention in applying this aspects. The research was focused on Grand Slipi Tower building, Jakarta where research variables comprises the influences of Human Systems, Equipment Systems and Standard Operating Procedures (SOP) either partially or simultaneously. To resolve this issues, a questionnaire was designed in respectively 15 questions for each variable. The questionnaire was distributed randomly to 55 respondents of 122 staff personels of Grand Slipi Tower. The responds of questionnaires resulted in scores for all variables that have been studied. To show the significance results of the simple regression, t-test was conducted and for multiple regression, F-test was conducted. The final results shows that Human System, Equipment System and SOP, either simultaneously or partially, affecting the compliances of fire protection codes and technical standards of the Grand Slipi Tower building with 99\% data accuracy. The effect of Human System partially, in percent was 71,3\%. The effect of Equipment System partially, in percent was $64.8 \%$. The SOP effect in percent was 48.5\%. While the effects of Human System, Equipment System and SOP simultaneously to the compliance of Fire regulations, codes and standards of the Grand Slipi Tower building in percent was $83.1 \%$
\end{abstract}

Keywords : Human System, Equipment System, SOP, fire protection regulations, codes and standards.

\begin{abstract}
Abstrak - Sistem proteksi kebakaran pada prinsipnya terdiri atas sistem proteksi aktif, atau sistem yang menggunakan energi (energized system), dikenal sebagai sistem proteksi aktif; sistem proteksi pasif yang merupakan built-in system, dan fire safety management (FSM) yang sering disebut sebagai human system. Pada tesis ini penulis menyoroti aspek FSM karena dari berbagai kejadian kebakaran, seringkali masalah utamanya adalah kurangnya penerapan dari aspek ini. Penelitian difokuskan pada bangunan Grand Slipi Tower, Jakarta dimana variable penelitiannya meliputi human system, equipment system dan prosedur operasi baku (SOP) baik parsial maupun secara simultan. Untuk menyelesaikan masalah ini dibuat kuesioner yang dirancang masing-masing 15 pertanyaan untuk setiap variable penelitian. Kuesioner ini disebarkan secara acak kepada 55 responden dari 122 staf pengelola gedung Grand Slipi Tower. Jawaban dari kuesioner menghasilkan skor untuk semua variable yang diteliti. Untuk menyatakan signifikansi hasil regresi sederhana diuji dengan uji-t dan untuk regresi ganda diuji dengan uji-F. Hasil yang didapat adalah Human System, Equipment System dan SOP baik simultan maupun parsial berpengaruh terhadap pemenuhan peraturan dan standar teknis proteksi kebakaran di Gedung Grand Slipi Tower dengan ketelitian 99\%. Pengaruh Human System secara parsial dalam persen adalah, 71,3\%. Pengaruh Equipment system secara parsial dalam persen adalah 64,8\%. Pengaruh SOP secara parsial dalam persen adalah, 48,5\%. Sedangkan pengaruh Human System, Equipment System dan SOP secara simultan terhadap pemenuhan Peraturan dan Standar teknis Proteksi Kebakaran di Gedung Grand Slipi Tower adalah 83,1\%
\end{abstract}

Kata kunci : human system, equipment system, SOP, peraturan dan standar teknis proteksi kebakaran 


\section{PENDAhUluan}

1.1 Latar Belakang

Kebakaran merupakan bencana yang senantiasa menimbulkan hal-hal yang tidak diinginkan, baik menyangkut kerusakan harta benda, kerugian materi, gangguan terhadap kelestarian lingkungan, terhentinya proses produksi barang serta jasa, serta bahaya terhadap keselamatan jiwa manusia. Bahaya kebakaran dapat terjadi setiap saat dan dimanapun termasuk di dalam gedung dikarenakan banyak peluang yang dapat memicu terjadinya kebakaran. Kebakaran di gedung tinggi sering berakibat fatal akibat sulitnya upaya pemadaman dari luar gedung.

Sebuah gedung mempunyai peranan yang sangat penting dalam mendukung kelancaran dan kesinambungan operasi perusahaan atau proses kerja secara keseluruhan. Oleh karena itu, semua pihak yang turut memanfaatkan gedung tersebut, baik individu ataupun badan perusahaan, termasuk mitra kerja harus aktif memelihara dan menjaga kebersihan, keselamatan dan kesehatan kerjanya. Salah satu perwujudan perusahaan dalam memelihara dan menjaga keselamatan dan kesehatan kerjanya adalah melalui penerapan Manajemen Keselamatan terhadap Kebakaran (Fire Safety Management/FSM)

Berbagai kejadian yang menimpa bangunan gedung tinggi akibat kebakaran atau emergency lainnya baik diakibatkan kelalaian atau sebab lain seperti kasus kebakaran sejumlah bangunan di Jakarta, telah menyadarkan pentingnya penerapan Fire Safety Management (FSM). Penerapan FSM telah dipersyatkan dalam Kepmeneg PU No. 11/KPTS/2000 tentang Ketentuan Teknis Manajemen Penanggulangan Kebakaran Perkotaan [1]. Kenyataan di lapangan menunjukkan bahwa sebagian besar bangunan tinggi belum menerapkan system FSM dengan baik dan konsisten. Undang-Undang Bangunan Gedung (UUBG-2002) yang mensyaratkan aspek keselamatan bangunan perlu ditindaklanjuti dengan penerapan pedoman teknis seperti FSM dan Rencana Tindak Darurat Kebakaran atau Fire Emergency Plan (FEP) yang merupakan subbagian dari FSM [2].

Fire Safety Management dapat dijadikan suatu input dalam mengantisipasi penanggulangan bahaya kebakaran pada saat operasional, sehingga pada saat terjadinya kebakaran dapat ditanggulangi secara mandiri dan dapat mengurangi jumlah kerugian yang di derita.Gedung Grand Slipi Tower yang terletak di J1. S. Parman Kav. 22-24 Jakarta 11480 setinggi 40 (empat puluh) lantai dengan luas total
79.492,32 m2 berfungsi sebagai perkantoran tentunya patut dikaji mengenai penerapan Fire Safety Management nya.

\subsection{Rumusan Masalah}

Dari permasalahan tersebut diatas, maka rumusan masalah yang ada adalah meneliti sejauh mana Fire Safety Management diterapkan di Bangunan Grand Slipi Tower dikaitkan dengan peraturan dan standar-standar teknis proteksi kebakaran yang berlaku, dengan mencari indikator-indikator terukur.

\subsection{Maksud dan Tujuan Penelitian}

Maksud penelitian ini adalah untuk menganalisa penerapan Fire Safety Management dalam proses pencegahan kebakaran dengan efektif di Gedung Grand Slipi Tower Jakarta disamping memberikan pengetahuan dan informasi dari pengaruh Fire Safety Management guna mengantisipasi jika terjadi bahaya kebakaran.

Tujuan dari penelitian ini adalah untuk mempelajari pengaruh dari Fire Safety Management dalam mencegah dan mengantisipasi bahaya kebakaran di lingkungan Bangunan Gedung Grand Slipi Tower dan memberikan usulan-usulan perbaikan dalam penerapannya.

\subsection{Batasan Penelitian}

Penelitian ini dilakukan untuk menganalisa penerapan Fire Safety Management guna mengantisipasi bahaya kebakaran pada bangunan perkantoran Gedung Grand Slipi Tower Jakarta.

\section{LANDASAN TEORI}

\subsection{Definisi Kebakaran}

Kebakaran adalah suatu nyala api, baik kecil atau besar pada tempat, situasi dan waktu yang tidak kita kehendaki, merugikan dan pada umumnya sukar dikendalikan. Jadi api yang menyala di tempat-tempat yang dikehendaki seperti kompor, di perindustrian dan tempat atau peralatan lain tidak termasuk dalam kategori kebakaran. Adapun definisi kebakaran yaitu reaksi kimia yang berlangsung cepat dan memancarkan panas dan sinar, reaksi kimia yang timbul termasuk jenis oksidasi [3]. Sedangkan definisi kebakaran menurut Asuransi secara umum adalah "Sesuatu yang benar-benar terbakar yang seharusnya tidak terbakar yang dibuktikan dengan adanya nyala api secara nyata, terjadi secara tidak sengaja, tiba-tiba serta menimbulkan kecelakaan atau kerugian" 


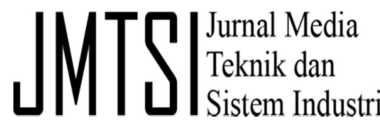

\subsection{Fire Safety Management}

Kegiatan FSM mencakup suatu dimensi yang luas baik ditinjau dari segi substansi maupun dari rentang waktu pemberlakuannya [4]. Secara substantif kegiatan FSM sekurang-kurangnya meliputi :

1. Pembentukan tim emergency dan pembinaan-nya

2. Pemeriksaan dan pemeliharaan peralatan proteksi secara berkala

3. Penyusunan fire \& other emergency plan (FOEP)

4. Penyelenggaraan latihan kebakaran \& evakuasi

5. Pelaksanaan fire safety audit

6. pelaksanaan fire-safe housekeeping dan dokumentasi bangunan

7. Penyusunan SOP keselamatan terhadap bahaya kebakaran

8. Sosialisasi unsur keselamatan terhadap bahaya kebakaran lewat pembuatan dan pemasangan leaflet, brosur dan poster

Sedangkan berdasarkan rentang waktu pemberlakuan kegiatan FSM bisa dilakukan sebelum kejadian, pada saat terjadi kebakaran dan setelah kejadian kebakaran. Apa yang disampaikan di atas adalah kegiatan FSM sebelum terjadinya kebakaran [4]. Kegiatan pada saat kejadian dan sesudahnya lebih bersifat operasi pemadaman kebakaran dan pemulihan pasca kebakaran.

\subsection{Fire \& Other Emergency Response Plan (FOEP)}

FEP (Fire Emergency Plan) merupakan salah satu unsur kegiatan yang termasuk dalam lingkup FSM. FEP harus disusun dan dimiliki oleh setiap bangunan terutama bangunan gedung tinggi, yang merupakan panduan untuk melaksanakan tindakan pencegahan dan penanggulangan kebakaran dan keadaan darurat lainnya agar tertib, efektif dan efisien. Dalam FEP diatur siapa berbuat apa dalam menghadapi kebakaran dan keadaan darurat lainnya. Dibentuk kelompok atau regu-regu sesuai dengan tugas kerja masingmasing, seperti regu komunikasi emergency, regu pemadaman kebakaran dan evakuasi, regu sekuriti, regu teknisi, dan regu pertolongan medis. Dalam FEP ada unsur pimpinan atau Koordinator, Pimpinan Lapangan atau Chief Warden, termasuk adanya Komandan / Kapten Lantai (Captain Floor).

Uraian tugas (job description) masing-masing regu dan anggotanya dituangkan dalam suatu prosedur. Sebagai contoh adalah penugasan berikut :
1. Tindakan saat pertama melihat adanya kebakaran

2. Tindakan pemberitahuan kejadian kebakaran - alarm tanda bahaya

3. Tindakan pemadaman kebakaran oleh tim internal dan tindakan per divisi

4. Operasi pemadaman oleh Pemadam Kebakaran \& penyerahan kembali

5. Tindakan evakuasi - alarm tanda bahaya 2

6. Tindakan menghadapi keadaan darurat medis akibat kebakaran

7. Tindakan penanggulangan kebakaran di luar jam kerja

8. Prosedur evaluasi pasca kebakaran

Kini dengan antisipasi terhadap berbagai gangguan dan ancaman, dirasa perlu untuk menambah lingkup FEP menjadi FOEP (Fire and Other Emergency Response Plan) dimana other emergency disini adalah banjir dan genangan air, gempa bumi, ledakan / eksplosi, gangguan instalasi, ancaman bom, penyusup berbahaya / bersenjata, kerusuhan masal, keadaan darurat medis (medical emergency), kiriman antrax, dsb.

\section{HASIL PENELITIAN DAN PEMBAHASAN}

3.1 Variabel Human System $\left(\mathrm{x}_{1}\right)$

Hasil pengolahan data variabel Human System disajikan pada Tabel I.

TABEL I

StaTISTIK VARIABEL HUMAN SYSTEM $\left(\mathrm{X}_{1}\right)$

\begin{tabular}{|l|l|r|}
\hline \multirow{N}{*}{} & Valid & 55 \\
\cline { 2 - 3 } & Missing & 0 \\
\hline Mean & 52.55 \\
\hline Std. Deviation & 9.584 \\
\hline Minimum & 35 \\
\hline Maximum & 70 \\
\hline Sum & 2890 \\
\hline
\end{tabular}

Data skor Human System tersebar dari 35 sampai dengan 70, deviasi standar (STDEV) adalah 9.584 dan rata-rata skor adalah 52.55. Histogram variabel Human System dapat dilihat pada Gambar 1 sebagai berikut.

\subsection{Variabel Equipment System $\left(\mathrm{x}_{2}\right)$}

Hasil pengolahan data variabel Equipment System ditabelkan pada Tabel II.

Tidak jauh berbeda dari data skor Human System, statistik variabel Equipment System tersebar dari 36 sampai dengan 62, deviasi standar (STDEV) adalah 7.647 dan rata-rata skor adalah 49.69. Histogram variabel Equipment System dapat dilihat pada Gambar 2. 


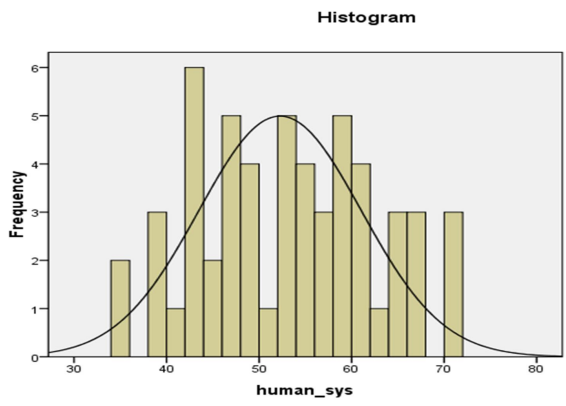

Gambar 1. Histogram variabel Human System.

TABEL II STATISTIK VARIABEL EQUIPMENT SYSTEM $\left(\mathrm{X}_{2}\right)$

\begin{tabular}{|l|l|r|}
\hline \multirow{2}{*}{$\mathrm{N}$} & Valid & 55 \\
\cline { 2 - 3 } & Missing & 0 \\
\hline Mean & 49.69 \\
\hline Std. Deviation & 7.647 \\
\hline Minimum & 36 \\
\hline Maximum & 62 \\
\hline Sum & 2733 \\
\hline
\end{tabular}

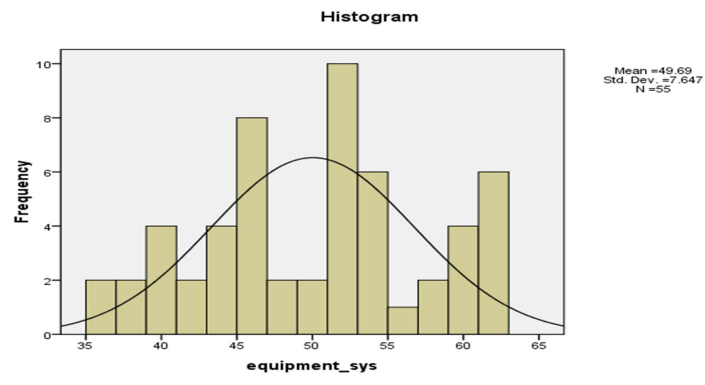

Gambar 2. Histogram variabel Equipment System.

\subsection{Variabel Prosedur SOP $\left(\mathrm{x}_{3}\right)$}

Hasil pengolahan data variabel prosedur SOP ditabelkan pada Tabel III sebagai berikut.

TABEL III STATISTIK VARIABEL $P$ ROSEDUR $\operatorname{SOP}\left(\mathrm{X}_{3}\right)$

\begin{tabular}{|l|l|r|}
\hline \multirow{2}{*}{} & Valid & 55 \\
\cline { 2 - 3 } & Missing & 0 \\
\hline Mean & 47.60 \\
\hline Std. Deviation & 9.162 \\
\hline Minimum & 34 \\
\hline Maximum & 69 \\
\hline Sum & 2618 \\
\hline
\end{tabular}

Tidak jauh berbeda dari data skor Human System, dan Equipment System statistik variabel prosedur SOP tersebar dari 34 sampai dengan 69, deviasi standar (STDEV) adalah 9.162 dan ratarata skor adalah 47.60. Histogram variabel prosedur SOP dapat dilihat pada Gambar 3 sebagai berikut.

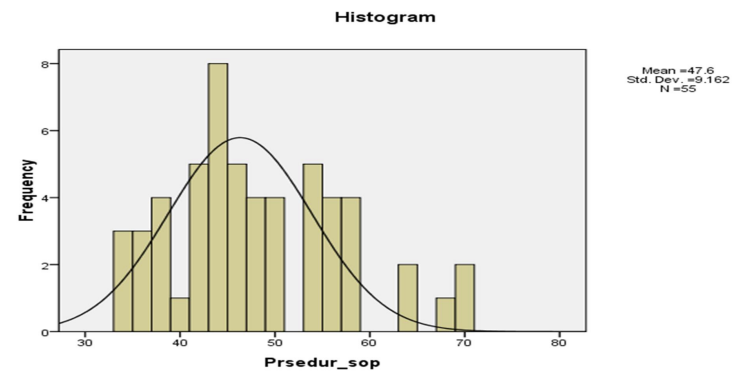

Gambar 3. Histogram variabel Prosedur SOP.

\subsection{Uji Validasi Pemenuhan Standar Teknis Proteksi (Y)}

Data kuesioner variabel pemenuhan standar teknis proteksi kebakaran di Gedung Grand Slipi Tower (Y) terdiri dari 15 (lima belas) buah pertanyaan dapat dilihat pada lampiran data. Variabel ini diuji validitasnya, validitas adalah ukuran yang menunjukkan sejauh mana instrumen (alat ukur) mampu mengukur apa yang ingin diukur. Tujuan pengujian validitas adalah untuk meyakinkan bahwa kuesioner yang kita susun akan benar-benar baik dalam mengukur gejala sehingga dihasilkan data yang valid. Untuk melakukan uji validitas, salah satu metode yang dapat digunakan adalah dengan mengkorelasikan antara skor butir-butir pertanyaan dengan skor pertanyaan secara total. Suatu butir pertanyaan dikatakan valid jika nilai $\mathrm{R}_{\text {hitung }}>\mathrm{R}_{\text {table }}$. Hasil pengujian data variabel standar teknis proteksi kebakaran di Gedung Grand Slipi Tower (Y) ditabelkan pada Tabel IV.

TABEL IV

HASIL UJI VALIDITAS UNTUK VARIABEL PEMENUHAN STANDAR TEKNIS PROTEKSI (STP) KEBAKARAN DI GEDUNG GRAND SLIPI TOWER (Y)

\begin{tabular}{|c|c|c|c|}
\hline Pertanyaan (Y) & R (hitung) & $\begin{array}{c}\mathrm{R} \\
\text { (tabel) }\end{array}$ & Keterangan \\
\hline $\begin{array}{c}\text { Pem. } \\
\text { stp_kebakaran_01 }\end{array}$ & $.617^{* *}$ & 0.345 & Valid \\
\hline $\begin{array}{c}\text { Pem. } \\
\text { stp_kebakaran_02 }\end{array}$ & $.546^{* *}$ & 0.345 & Valid \\
\hline $\begin{array}{c}\text { Pem. } \\
\text { stp_kebakaran_03 }\end{array}$ & $.735^{* *}$ & 0.345 & Valid \\
\hline $\begin{array}{c}\text { Pem. } \\
\text { stp_kebakaran_04 }\end{array}$ & $.670^{* *}$ & 0.345 & Valid \\
\hline
\end{tabular}




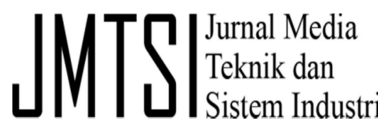

\begin{tabular}{|c|c|c|c|}
\hline $\begin{array}{c}\text { Pem. } \\
\text { stp_kebakaran_05 }\end{array}$ & $.757^{* *}$ & 0.345 & Valid \\
\hline $\begin{array}{c}\text { Pem. } \\
\text { stp_kebakaran_06 }\end{array}$ & $.761^{* *}$ & 0.345 & Valid \\
\hline $\begin{array}{c}\text { Pem. } \\
\text { stp_kebakaran_07 }\end{array}$ & $.689^{* *}$ & 0.345 & Valid \\
\hline $\begin{array}{c}\text { Pem. } \\
\text { stp_kebakaran_08 }\end{array}$ & $.652^{* *}$ & 0.345 & Valid \\
\hline $\begin{array}{c}\text { Pem. } \\
\text { stp_kebakaran_09 }\end{array}$ & $.660^{* *}$ & 0.345 & Valid \\
\hline $\begin{array}{c}\text { Pem. } \\
\text { stp_kebakaran_10 }\end{array}$ & $.793^{* *}$ & 0.345 & Valid \\
\hline $\begin{array}{c}\text { Pem. } \\
\text { stp_kebakaran_11 }\end{array}$ & $.782^{* *}$ & 0.345 & Valid \\
\hline $\begin{array}{c}\text { Pem. } \\
\text { stp_kebakaran_12 }\end{array}$ & $.749^{* *}$ & 0.345 & Valid \\
\hline $\begin{array}{c}\text { Pem. } \\
\text { stp_kebakaran_13 }\end{array}$ & $.698^{* *}$ & 0.345 & Valid \\
\hline $\begin{array}{c}\text { Pem. } \\
\text { stp_kebakaran_14 }\end{array}$ & $.767^{* *}$ & 0.345 & Valid \\
\hline $\begin{array}{c}\text { Pem. } \\
\text { stp_kebakaran_15 }\end{array}$ & $.769^{* *}$ & 0.345 & Valid \\
\hline $\begin{array}{c}\text { Peman } \\
\text { peman }\end{array}$ & &
\end{tabular}

\section{KESIMPULAN DAN SARAN}

\subsection{Kesimpulan}

Setelah melakukan analisis dan pengujian statistik pengaruh variabel bebas Human System $\left(\mathrm{X}_{1}\right)$ dan Equipment System $\left(\mathrm{X}_{2}\right)$ terhadappemenuhan standar teknis proteksi (stp) kebakaran di Gedung Grand Slipi Tower (Y) baik secara terpisah maupun bersama-sama seperti apa yang diuraikan dalam hipotesis. Secara terperinci dapat diuraikan sebagai berikut:

a) Pengaruh parsial Human System $\left(\mathrm{X}_{1}\right)$ terhadap pemenuhan standar teknis proteksi kebakaran di Gedung Grand Slipi Tower $(\mathrm{Y})$ dinyatakan dengan persamaan linier regresi sederhana sebagai $\mathrm{Y}=$ $13,882+0,0,775 X_{1}$. Persamaan regresi ini signifikan dengan keabsahan 99\% karena uji-t membuktikan bahwa $\mathrm{t}_{\text {hitung }}>\mathrm{t}_{\text {tabel }}$ $(11,484>2,399)$. Pengaruh dalam persen sebesar $71,3 \%$, sisanya $28,3 \%$ disebabkan oleh faktor lain.

b) Pengaruh parsial Equipment System $\left(\mathrm{X}_{2}\right)$ terhadap pemenuhan standar teknis proteksi kebakaran di Gedung Grand Slipi Tower $(\mathrm{Y})$, dinyatakan dengan persamaan linier regresi sederhana sebagai $\mathrm{Y}=8,618$ $+0,925 \mathrm{X}_{2}$. Persamaan regresi ini signifikan dengan keabsahan $99 \%$ karena uji-t membuktikan bahwa $\mathrm{t}_{\text {hitung }}>\mathrm{t}_{\text {tabel }}$ $(9,871>2,399)$. Pengaruh dalam persen sebesar $64,8 \%$, sisanya $35,2 \%$ disebabkan oleh faktor lain.

c) Pengaruh parsial Prosedur SOP $\left(\mathrm{X}_{3}\right)$ terhadap pemenuhan standar teknis proteksi kebakaran di Gedung Grand Slipi Tower (Y), dinyatakan dengan persamaan linier regresi sederhana sebagai $\mathrm{Y}=$

$22,778+0,668 \mathrm{X}_{3}$. Persamaan regresi ini signifikan dengan keabsahan 99\% karena uji-t membuktikan bahwa $t_{\text {hitung }}>t_{\text {tabel }}$ (7.067>2,399). Pengaruh dalam persen sebesar $48,5 \%$, sisanya $51,5 \%$ disebabkan oleh faktor lain.

d) Pengaruh simultan Human System $\left(\mathrm{X}_{1}\right)$, Equipment System $\left(\mathrm{X}_{2}\right)$ dan Prosedur SOP $\left(\mathrm{X}_{3}\right)$ terhadap pemenuhan standar teknis proteksi kebakaran di Gedung Grand Slipi Tower (Y) dinyatakan dengan persamaan regresi ganda sebagai $\mathrm{Y}=1,238+0,418$ $\mathrm{X}_{1}+0.405 \mathrm{X}_{2}+0.236 \mathrm{X}_{3}$. Persamaan regresi ini signifikan dengan keabsahan 99\% karena uji-F membuktikan bahwa $\mathrm{F}_{\text {hitung }}>\mathrm{F}_{\text {tabel }}(89,40>4,19) . \quad$ Pengaruh dalam persen sebesar $83,1 \%$, sisanya $16,9 \%$ disebabkan oleh faktor lain yang belum diketahui

\subsection{Saran}

Kepada Pengelola Gedung Grand Slipi Tower disarankan bahwa :

a) Standar teknis proteksi kebakaran di Gedung Grand Slipi Tower dipengaruhi oleh 3(tiga) variabel bebas Human System, Equipment System dan prosedur SOP. Dari ketiga variabel bebas ini urutan besarnya pengaruh disebabkan oleh Human System, Equipment System dan prosedur SOP. Masing-masing pengaruh dalam persen adalah $\quad 71,3 \%, \quad 64,8 \%$ dan $48,5 \%$. Disarankan urutan prioritas adalah Human System didahulukan baru Equipment System dan kemudian Prosedur SOP.

b) Jika ketiga pengaruh variabel bebas Human System, Equipment System dan Prosedur SOP diperhatikan secara bersama-sama menghasilkan pengaruh yang lebih besar yaitu $83,1 \%$. Hal ini menunjukkan pada kita bahwa ketiga pengaruh Human System, Equipment System dan prosedur SOP saling mendukung sehingga menghasilkan pengaruh bersama-sama yang lebih besar dari pada pengaruh secara parsial.

c) Untuk meningkatkan pemenuhan standar teknis proteksi kebakaran di Gedung Grand Slipi Tower adalah dengan memperhatikan Human System, Equipment System dan prosedur SOP dengan lebih seksama.

d) Implementasi manajerial untuk mendapatkan hasil pemenuhan standar teknis proteksi kebakaran di Gedung Grand Slipi Tower sudah cukup ideal dengan mengambil ketiga variabel bebas Human 
System, Equipment System dan prosedur SOP.

\section{REFERENSI}

[1] Departemen Pekerjaan Umum, KepMen No. 10/KPTS/2000. Ketentuan Teknis Pengamanan Terhadap Bahaya Kebakaran Pada Bangunan Gedung dan Lingkungan. Kementrian Pekerjaan Umum RI. 2000

[2] Presiden Republik Indonesia. UndangUndang Republik Indonesia Nomor 28 TAHUN 2002 Tentang Bangunan Gedung. Sekretariat Negara RI. 2002

[3] Colling, David A. 'Industrial Safety: Management and Technology 1st Ed.' Prentice Hall. 1990

[4] Lasino \& F. Suhedi. 'Kajian Penerapan Manajemen Keselamatan Kebakaran (Fire Safety Management) pada Bangunan Gedung Tinggi di Indonesia'. Proseding Seminar Kolokium \& Open House, Departemen Pekerjaan Umum. 2005

[5] Walton, W. D., dan P. H. Thomas, \& Y. Ohmiya. 'Estimating Temperatures in Compartement Fire' dalam Morgan J. H. dkk (Eds.). 'SFPE Handbook of Fire Protection Engineering 5th Edition. Springer. 2016 